\title{
PRÁTICAS LEITORAS E O USO DO INFOGRÁFICO: DA MULTIMODALIDADE AOS MULTILETRAMENTOS
}

\author{
READER PRACTICES AND THE USE OF INFOGRAPHIC: FROM \\ MULTIMODALITY TO MULTILITERACIES
}

\author{
Ana Lucia Rodrigues Guterra ${ }^{1}$ \\ Ernani Cesar de Freitas ${ }^{2}$
}

\begin{abstract}
RESUMO: A infografia configura-se como um meio de informação utilizado cada vez mais em jornais, revistas e sites de notícias. Diante disso, este trabalho tematiza a experiência de leitura de um infográfico enquanto gênero discursivo multimodal no contexto escolar. $\mathrm{O}$ objetivo é analisar uma prática de leitura a partir de um exercício de aplicação de um texto multimodal no $2^{\circ}$ ano do ensino médio de uma escola pública. O marco teórico do estudo é constituído por conceitos relacionados aos gêneros do discurso (BAKHTIN, 2016), ao letramento (LEMKE, 2010; RIBEIRO, 2011, 2016), à multimodalidade discursiva (KRESS; van LEEUWEN, 2001, 2006; DIONÍSIO, 2011, 2013), à pedagogia dos multiletramentos (COPE; KALANTZIS, 2000; THE NEW LONDON GROUP, 2000; ROJO, 2009, 2012, 2013) e ao ensino com a Nova Base Nacional Comum Curricular (BRASIL, 2018). Trata-se de um estudo exploratório realizado mediante pesquisa-ação, de cunho qualitativo e quantitativo. A hipótese é de que a utilização de infográfico como um dos gêneros discursivos multimodais promove de forma eficaz o desenvolvimento dos multiletramentos nos alunos, ampliando suas competências leitoras e os aproximando de situações sociodiscursivas próprias do seu cotidiano.
\end{abstract}

Palavras-chave: Leitura. Multimodalidade. Multiletramentos.

ABSTRACT: Infographics are increasingly being used as a means of information that is constantly used in newspapers, magazines and news sites. Therefore, this work thematizes the experience of reading an infographic as a multimodal discursive genre in the school context. The objective is to analyze a reading practice of students from an exercise of applying a multimodal text in the second year of high school in a public school. The theoretical framework of the study is constituted by concepts related to the genres of discourse (BAKHTIN, 2016), to literacy (LEMKE, 2010; RIBEIRO, 2011, 2016), and to discursive multimodality (KESSESS; van LEEUWEN, 2001, 2006; DIONÍSIO, 2011, 2013), the pedagogy of multiliteracies (COPE; KALANTZIS, 2000; THE NEW LONDON GROUP, 2000, ROJO, 2009, 2012, 2013) and teaching with the New Common National Curriculum Base (BRAZIL, 2018). It is an exploratory study, carried out through action research, of a qualitative and quantitative nature. The hypothesis is that the use of infographic as one of the multimodal discursive genres efficiently promotes multiliteracies in students, developing their reading skills and bringing them closer to sociodiscursive situations typical of their daily life.

Keywords: Reading; Multimodality. Multiliteracies.

\section{Introdução}

A Base Nacional Comum Curricular - BNCC - (BRASIL, 2018), documento que atualmente rege o ensino brasileiro, é uma extensão dos Parâmetros Curriculares Nacionais PCN (1997). Tanto a BNCC como os PCNs, no que tange à área das Linguagens, se fundamentam em concepções bakhtinianas. O atual documento preconiza práticas de linguagens como forma de interação e ação no mundo, em que a compreensão da leitura é

1 Doutoranda em Letras no Programa de Pós-Graduação em Letras da Universidade de Passo Fundo (UPF). Mestre em Literatura Comparada pela Universidade Regional Integrada (URI). Seberi, Brasil, e-mail: anaguterra@gmail.com

2 Doutor em Letras (PUCRS) com pós-doutorado em Linguística Aplicada e Estudos da Linguagem PUCSP/LAEL); professor do PPG em Letras da Universidade de Passo Fundo (RS) e do PPG em Processos e Manifestações Culturais da Universidade Feevale, Novo Hamburgo (RS); e-mail: nanicesar@terra.com.br 
concebida como ato dialógico e a concepção de sujeito é constituído pelas práticas de linguagem. A Base Nacional Comum Curricular (BRASIL, 2018) propõe uma diversidade de gêneros discursivos, e um deles que temos visto circular em abundância na contemporaneidade é o infográfico. Conforme Sancho (2013) o infográfico é um gênero discursivo informativo feito com elementos icônicos e tipográficos que facilitam a compreensão de eventos, ações ou coisas atuais. Diante disso, este trabalho tematiza a experiência de leitura de um infográfico, enquanto gênero discursivo de natureza multimodal, no contexto escolar do Ensino Médio, pela necessidade de a instituição escolar tomar a seu cargo os novos letramentos emergentes na sociedade contemporânea. Rojo (2009, p.8) afirma que em pleno século XXI é preciso enfrentar no ensino brasileiro dois problemas: "evitar a exclusão escolar e tornar a experiência na escola um percurso significativo em termos de letramentos e de acesso ao conhecimento e à informação". É de grande valia a inclusão e a autonomia do sujeito no mundo contemporâneo; sendo assim, saber ler e atribuir significado ao que se lê pressupõe apropriação e inserção da pessoa como sujeito protagonista.

O presente estudo justifica-se porque a presença multimodal na comunicação contemporânea exige específicas e refinadas habilidades leitoras dos sujeitos e de formação leitora das escolas, cujos currículos, muitas vezes, ignoram ou tratam superficialmente os novos letramentos que, em tese, visam dar conta das demandas interativo-comunicativas hodiernas.

Diante dessa proposta, temos como problematização o seguinte questionamento: Como a prática leitora com texto multimodal infográfico, pouco utilizado nas aulas de língua materna, pode contribuir para o letramento e os multiletramentos dos alunos de uma escola pública. Isso posto, temos como objetivo analisar uma prática leitora de alunos do $2^{\circ}$ ano do ensino médio, com base em exercício de aplicação de um texto multimodal infográfico que é produtivo para desenvolver o letramento e os multiletramentos desse público formado por jovens estudantes.

O marco teórico desse estudo é constituído por conceitos relacionados ao ensino (BRASIL, 2018), aos gêneros do discurso (BAKHTIN, 2016), ao letramento (LEMKE, 2010; RIBEIRO, 2011, 2016), à multimodalidade discursiva (KRESS; van LEEUWEN, 2001, 2006; DIONÍSIO, 2011, 2013) e à pedagogia dos multiletramentos (COPE; KALAZANTIS, 2000; THE NEW LONDON GROUP, 2000; ROJO, 2009, 2012, 2013). Trata-se de um estudo exploratório, realizado mediante pesquisa-ação com abordagem qualitativa, e quantitativa no que diz respeito aos indicadores. Essa pesquisa-ação desenvolveu-se durante 2 semanas, no período entre 6 de junho (diagnóstico da turma) a 10 de agosto de 2018.

\section{Gênero discursivo: infográfico e práticas leitoras}

A BNCC (2018) é um documento suporte que orienta as práticas pedagógicas e ajuda a melhorar e ampliar a linguagem e desenvolver o pensamento crítico. Conforme sua orientação, a sala de aula é espaço de interação social em que os estudantes, de maneira participativa, são produtores ativos responsivos de linguagens e isso exige deles uma postura diante dos enunciados na prática dialógica.

No componente de Língua Portuguesa para o Ensino Médio, a BNCC (2018) leva em conta "a consolidação do domínio de gêneros do discurso/gêneros textuais já contemplados anteriormente e a ampliação do repertório de gêneros" (BRASIL, 2018, p. 491). Essa concepção de ensino e aprendizagem está baseada em pressupostos da teoria dos gêneros discursivos de Mikhail Bakhtin (2016). O pensador e teórico russo, em sua obra Estética da criação verbal (2016), aborda os gêneros do discurso, afirmando que "todos os diversos campos da atividade humana estão ligados ao uso da linguagem. Compreende-se perfeitamente que o caráter e as formas desse uso sejam tão multiformes quanto os campos da atividade humana [...]" (BAKHTIN, 2016, p. 11) em que se dá a comunicação social definida 
Volume 14 - Número 2 - ago/dez de 2019

pelo gênero do discurso apropriado para cada momento. Sendo assim, esse autor compreende os diferentes usos da linguagem, na sua variedade (multiformes), que se efetuam sob a forma de enunciados concretos e únicos expressos pelos sujeitos que participam das interações sociais.

Bakhtin (2016) evidencia que todo o texto pertence a uma configuração de determinado gênero, sendo que os gêneros discursivos são formas "relativamente estáveis" de enunciados, definidos por três elementos constitutivos: "o conteúdo temático, o estilo e a construção composicional” (BAKHTIN, 2016, p. 12). Essas características se manifestam simultaneamente na produção de um enunciado, e mostram-se, primeiramente, pelo seu conteúdo temático, o que não significa que se deve levar em conta o assunto do texto, mas a maneira pela qual o assunto é tratado no texto. Já a construção composicional caracteriza-se pela forma pela qual o texto se estrutura. Quanto ao estilo, Bakhtin $(2016$, p. 21) comenta que "onde há estilo há gênero", pois o estilo decorre, utilizando uma seleção de recursos linguísticos que criam um efeito de individualidade como uma visão de mundo.

Quando esse teórico trata dos gêneros do discurso, está em destaque a sua dimensão dialógica, ou seja, no evento que ocorre na esfera dos interlocutores, no efeito do diálogo. Para o autor, o "diálogo é a forma clássica de comunicação discursiva" (BAKHTIN, 2016, p. 29). Assim, o dialogismo de Bakhtin é visto de duas maneiras: primeiro, como o diálogo entre os interlocutores; depois, como o diálogo entre os discursos em si que referem a discursos anteriores já produzidos. Ainda segundo Bakhtin, toda compreensão de um texto acarreta uma responsividade, uma atitude de resposta: "Cada réplica, por mais breve e fragmentária que seja, tem uma conclusibilidade específica ao exprimir certa posição do falante que suscita resposta, em relação à qual se pode assumir uma posição responsiva" (BAKHTIN, 2016, p. 30). Nesse ponto, é interessante lembrarmos que a BNCC expressa as noções de linguagem enquanto interação no uso social de gêneros discursivos.

O gênero do discurso utilizado na prática leitora deste estudo é o infográfico, e sua escolha se deu porque é um texto multimodal por excelência, como afirma Ribeiro (2016, p. 31): "seu planejamento já o constrói com, pelo menos, palavras e imagens em um leiaute (na web, é possível agregar som, movimento, etc.)". Também, de acordo com Ribeiro (2016, p. 31 ), porque é "um gênero que circula amplamente em jornais e revistas impressos, digitais e ao mesmo tempo na TV, nas previsões do tempo, nas explicações e nas demonstrações de fatos, causas, efeitos, trajetórias, etc.”. Os infográficos são constituídos por elementos icônicos e tipográficos que de forma simultânea facilitam a compreensão de dados ou fenômenos e auxiliam no processo de comunicação tornando a informação dinâmica e atrativa.

A partir da prática realizada percebemos que o gênero discursivo infográfico ainda não é muito familiar aos estudantes nas aulas de língua materna e seria fundamental que os alunos fossem multiletrados em textos multimodais, como os infográficos, para que desenvolvam proficiência leitora e produtora de textos no mundo letrado. Nesse sentido, elaboramos uma prática leitora com o infográfico, texto multimodal, por acreditarmos no desenvolvimento da leitura/do leitor nas aulas de língua materna.

Dionísio e Vasconcelos (2013) expressam a importância da leitura realizada no ambiente escolar em que há trocas constantes de aprendizagem. Segundo essas pesquisadoras, é importante que, na escola, através de todas as possibilidades de diálogo, o estudante experiencie oportunidades que sejam "elaboradas e avaliadas continuamente pelos professores e todos os profissionais envolvidos na tarefa educativa. Não devem ser escolhas aleatórias, improvisação, prática sem respaldo teórico, ação rígida e sem abertura para novos conhecimentos ou novas descobertas da ciência" (DIONÍSIO; VASCONCELOS, 2013, p. 66). Assim, dá-se ênfase a práticas preparadas e construídas de forma planejada. 
Volume 14 - Número 2 - ago/dez de 2019

A partir desses pressupostos ligados ao processo comunicativo por meio dos gêneros discursivos, mais especificamente os infográficos, refletiremos a seguir sobre outras questões essenciais a respeito da competência da leitura e do enfoque da multimodalidade e do (multi) letramento no ensino.

\section{Multimodalidade e multiletramentos: a formação do leitor crítico}

Saber ler e atribuir significado ao que se lê é de suma importância, porque se trata de uma competência fundamental à inclusão e à autonomia do indivíduo. Por isso, a escola, principal agência de letramento, necessita oportunizar o desenvolvimento dessa habilidade no aluno. Kleiman (2002, p. 65) define a atividade da leitura como "uma interação a distância entre o leitor e autor via texto". Essa autora declara que o aluno não apenas recebe, mas ele constrói um significado integral para o texto, e isso acontece pelas pistas do texto. É através delas que o leitor "procura pistas formais, antecipa essas pistas, formula e reformula hipóteses, aceita e rejeita conclusões" (KLEIMAN, 2002, p. 65). Assim, a leitura envolve dinamicidade para o processamento do texto e as práticas leitoras na escola devem oportunizar aos estudantes a chance de eles tornarem-se leitores críticos de textos multimodais nos diversos gêneros discursivos que se deparam no cotidiano.

Tão importante quanto a percepção dos gêneros do discurso como instrumento que auxilia aos que produzem e aos que leem os textos, é a interação com os gêneros por meio da leitura competente. Nesse sentido, os textos multimodais são discursos que dispõem de atrativos de semioses variadas para que a leitura se torne mais eficaz. Gunther Kress e Theo van Leeuwen são autores de livros considerados os marcos iniciais dos estudos multimodais. A partir de seus estudos, entendemos que a multimodalidade é a designação para

[...] o uso de diversas modalidades semióticas no design de um produto ou evento semiótico, juntamente com a forma particular como essas modalidades são combinadas- elas podem, por exemplo, se reforçar ("dizer o mesmo de maneiras diferentes"), desempenhar papéis complementares [...] ou ser ordenadas hierarquicamente [...] (KRESS; van LEEUWEN, 2006, p. 20).

Os textos multimodais ofertam atrativos que são organizados na produção de sentidos e contribuem para o desenvolvimento do espírito crítico do aluno, bem como para o exercício de leitura significativa. Eles incorporam vários modos, como "palavras, imagens, sons, cores, músicas, aromas, movimentos variados, texturas, formas diversas" (DIONÍSIO; VASCONCELOS, 2013, p, 19) e é essa a materialização de vários elementos que irão mostrar as intenções do autor no processo interativo.

A multimodalidade possui estreita ligação com a ideia de multiletramentos. The New London Group (2000), formado em 1996, é um grupo que reúne vários pesquisadores que discutiram as possibilidades e a necessidade de práticas pedagógicas voltadas para os multiletramentos e trouxeram contribuições que resultaram na expressão "pedagogia dos multiletramentos". Os resultados das discussões desse grupo foram encapsulados nesse sintagma que "descreve dois argumentos importantes que poderíamos ter como a ordem cultural, institucional e global emergente". (COPE; KALANTZIS, 2000, p. 5). O primeiro argumento envolve a multiplicidade de canais de comunicação e mídia, os quais crescem e integram as formas de fazer sentido. O segundo argumento refere-se à crescente relevância da diversidade cultural e linguística, em que há um aumento da diversidade local e conexão global. Por fim, Cope e Kalantzis (2000, p. 6) concluem: "E, em termos mais construtivos, temos de negociar, todos os dias, nas nossas comunidades locais e em nossas vidas comunitária e do trabalho cada vez mais globalmente conectadas" 
Desse modo, esses teóricos afirmam que há a necessidade de formar o leitor multiletrado, que aprenderá os aspectos culturais e sociais específicos, além de conhecer diferentes modos de significação com os quais irá interagir com a finalidade de alcançar propósitos culturais e comunicativos. Ribeiro (2011, p. 136) afirma que o letramento significa a experiência "com objetos de leitura, também deve possibilitar que o leitor deduza e explore o que pode haver de híbrido e reconhecível em cada gênero ou em cada suporte, e, assim, manipulá-lo como quem conquista, e não como quem tem medo".

Lemke (2010, p. 455), ao se referir a letramentos, afirma que "letramentos são legiões" e são sempre sociais, nós todos os aprendemos pelas relações sociais. Também define letramento como um "conjunto de competências culturais para construir significados sociais reconhecíveis através do uso de tecnologias materiais e particulares" (LEMKE, 2010, p. 456). Esse autor sustenta que é necessário compreender (para, então, ensinar) como as várias tecnologias de letramentos combinam seus sistemas semióticos para construir sentidos, que podem ou não ter como esquema principal o sistema linguístico.

Lemke (2010, p. 462) ainda afirma que "texto e figura juntos não são duas formas de dizer a mesma coisa; o texto significa mais quando justaposto à figura, e da mesma forma a figura quando colocada ao lado de um texto". Dessa forma, de acordo com esse teórico, precisamos pensar em "como as tecnologias da informação podem transformar nossos hábitos institucionais de ensinar e aprender". (LEMKE, 2010, p. 468). Hoje, a dificuldade dos professores em lidar com as tecnologias e a precariedade das escolas faz muitas vezes com que se proíba o uso de eletrônicos ao invés de incentivá-lo.

Diante desse contexto, Lemke (2010, p. 269) evidencia que multiletramentos e gêneros multimodais podem ser ensinados, mas é necessário que os professores e alunos saibam o que eles são, para que são usados, que recursos empregam, como eles podem ser integrados um ao outro, como são tipicamente formatados, quais são seus valores e limitações.

Cope e Kalantzis (2000) sustentam que todos os textos são multimodais e que o conceito de multimodalidade nos faz repensar as distinções feitas entre comunicação e uso, em particular entre leitura e uso, o que é crucial para a teoria dos multiletramentos: "Os agentes de letramento e os estudantes devem se ver como participantes ativos na mudança social; como aprendizes e estudantes que podem ser produtores ativos de projetos de futuros sociais" (COPE; KALANTZIS, 2000, p. 6).

Desse modo, buscamos a formação de sujeitos críticos com suas competências leitoras desenvolvidas, acreditamos que o leitor multiletrado compreenderá os novos modos de interação/de comunicação nos variados gêneros discursivos e, assim, possuirá acesso a todos os bens que fazem parte das práticas sociais. Na próxima seção, destacamos os procedimentos metodológicos que configuram este estudo.

\section{Procedimentos metodológicos}

Em relação à metodologia utilizada no desenvolvimento deste estudo, de acordo com Prodanov e Freitas (2013, p. 126-127), trata-se de uma pesquisa exploratória desenvolvida mediante pesquisa-ação, com abordagem qualitativa predominante e quantitativa, com a finalidade de produzir conhecimentos práticos relacionados a possíveis situações-problema associadas ao desenvolvimento de prática leitora eficaz em sala de aula, levada a efeito em uma escola de Ensino Médio, vinculada à Secretaria de Educação do Estado do Rio Grande do Sul e localizada na cidade de Seberi, RS.

Alguns dos principais pressupostos teóricos abordados conceitualmente nas seções $2 \mathrm{e}$ 3 serão utilizados na análise, tais como: os conceitos relacionados ao ensino (BNCC, 2018), aos gêneros do discurso (BAKHTIN, 2016), ao letramento (LEMKE, 2010; RIBEIRO, 2011, 2016), à multimodalidade discursiva (KRESS; van LEEUWEN, 2001, 2006; DIONÍSIO, 
2011, 2013) e à pedagogia dos multiletramentos (COPE; KALAZANTIS, 2000; THE NEW LONDON GROUP, 2000; ROJO, 2009, 2012, 2013).

O corpus objeto de análise trata-se do infográfico "Água" retirado do livro $O$ mundo em infográficos (RICHARDS; SIMKINS, 2013, p. 108-109), visando aplicar a atividade na sala de aula, mediante campo de observação da realidade estudada para aprimorar a prática desenvolvida. Essa turma de alunos do segundo ano do Ensino Médio está vinculada a uma escola pública estadual denominada Instituto Estadual de Educação Madre Tereza - IEEMT. Escolhemos pesquisar uma turma do $2^{\circ}$ ano do ensino médio na disciplina de Língua Portuguesa, por fazer parte da metade da trajetória da última etapa da educação básica e ser um ano/série em que a pesquisadora, autora deste estudo, atua há muitos anos, mas principalmente pelo infográfico ser um gênero discursivo recorrente na prova do ENEM, em quase todas as edições, inclusive em seus textos motivadores para a produção do texto dissertativo-argumentativo.

Os sujeitos envolvidos neste estudo foram a professora pesquisadora, a professora titular e os alunos da turma 204, composta por 18 alunos, sendo, 11 meninos e 8 meninas e a faixa etária da turma vai dos 16 anos aos 18 anos, sendo que a maioria dos alunos possui 16 anos. É uma turma do $2^{\circ}$ ano do ensino médio do Instituto Estadual de Educação Madre Tereza localizado na cidade de Seberi-RS. A pesquisa apresenta fases distintas na sua investigação. Fizemos, inicialmente, um levantamento bibliográfico através de consultas a materiais já publicados a respeito das categorias teóricas, fundamentais para, posteriormente, proceder à descrição e análise do corpus selecionado. Escolhemos a metodologia da pesquisaação pelo fato de que a ideia principal deste trabalho é sim contribuir com novas atividades que proporcionem esta prática e avaliar sua aplicação a partir das considerações dos alunos.

Primeiramente, a partir dos objetivos propostos, selecionamos o corpus motivador (infográfico), com o qual se trabalhou na prática leitora. A partir da metodologia proposta, é importante compreender o que nos levou a utilizar a coleta de dados nesta pesquisa. Considerando o tratamento dado à leitura significativa no ensino médio, elaboramos atividades práticas com o infográfico que consta em anexo. Para isso, utilizamos quadrosíntese para apresentar as questões mais destacadas e produtivas, conforme nosso entendimento, para fins de análise no sentido de realizarmos algumas reflexões da prática leitora em texto multimodal.

Organizamos nossas ações para a análise de acordo com os procedimentos a seguir:

a) inicialmente, no dia oito de agosto de 2018, em dois períodos de Língua Portuguesa, aplicamos a leitura de infográficos através de slides para ambientar os alunos às informações. O objetivo da aula foi reconhecer um infográfico, identificar informações provenientes dele, perceber os processos representados no infográfico e sua circulação.

b) retornamos no dia dez de agosto, em dois períodos, e aplicamos a leitura individual do infográfico (Figura 1) "Água” (RICHARDS; SIMKINS, 2013, p. 108-109). A razão pela qual escolhemos esse infográfico é porque possui um tema relacionado ao meio ambiente, sendo que este é um assunto que perpassa os currículos do Ensino Médio. Cada aluno recebeu um infográfico colorido em folha A4 e respondeu individualmente a 16 questões.

c) a análise recai sobre as respostas dadas pelos alunos, nas quais atrelamos às categorias teóricas relacionadas aos gêneros do discurso com seus elementos constitutivos: conteúdo temático, construção composicional e estilo, com sua responsividade e dialogismo ao ensino, ao letramento, à multimodalidade discursiva e à pedagogia dos multiletramentos.

A partir dos procedimentos evidenciados, passamos à análise da materialidade, do corpus. 
Volume 14 - Número 2 - ago/dez de 2019

\section{Infográfico "Água": uma análise da dinamicidade e comunicação da informação traduzida em conhecimento}

Dedicamo-nos, a partir deste momento, a analisar a atividade resultante da aplicação do infográfico "Água” (RICHARDS; SIMKINS, 2013, p. 108-109) selecionado do livro: $O$ mundo em infográficos" conforme Figura a seguir:

\section{Figura 1 - Infográfico “Água”}

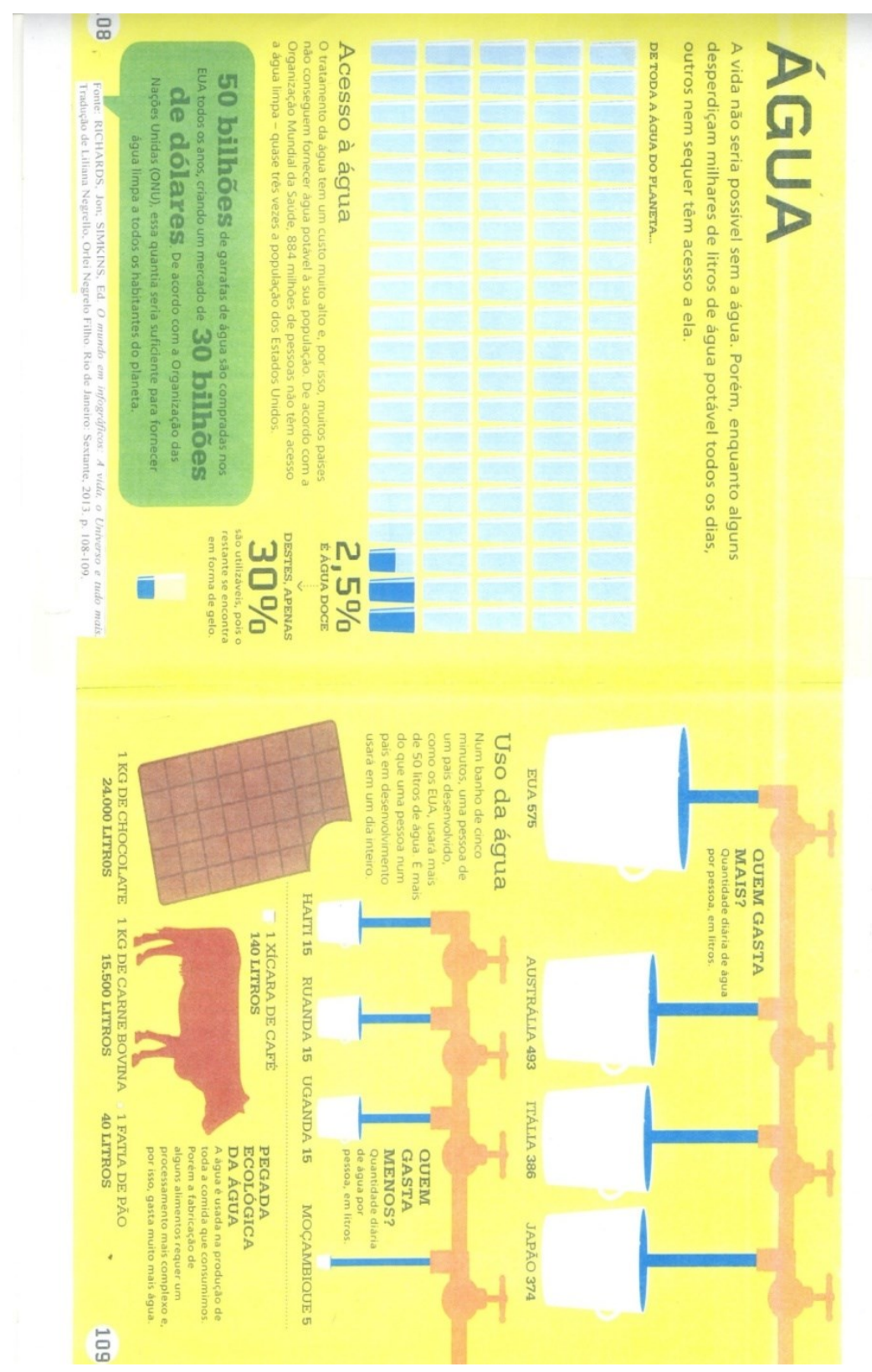

Fonte: O Mundo em infográficos (RICHARDS; SIMKINS, 2013, p. 108-109)

No dia 08 de agosto de 2018, em dois períodos de Língua Portuguesa, expusemos alguns infográficos por meio de slides para familiarizar os alunos às informações. Os textos foram retirados de sites variados e blogues. O objetivo foi reconhecer um infográfico, identificar informações provenientes dele, perceber os processos representados no infográfico e sua circulação. No início, fizemos com que, em primeiro lugar, os alunos realizassem uma 
leitura silenciosa do infográfico projetado através de data show; em seguida, solicitamos que expusessem sua leitura, e, finalmente, a pesquisadora atentava, oralmente, para os detalhes do visual e verbal (multimodalidade) que compunham o texto.

Nessa aula, apresentamos temas variados para a leitura e que fossem pertinentes para os alunos - os infográficos escolhidos trataram de temáticas variadas. A professora titular da turma expressou o quanto julgou ser importante e interessante trabalhar esse gênero em sala de aula. Com essa prática, entramos em consonância com Dionísio (2011, p. 149) quando questiona se estará o professor consciente no que implica uma aula ministrada com slides ou power point, pois isso requer do aluno uma atividade bastante intrincada, já que é preciso coordenar variadas práticas de letramento nas quais o aluno necessita se integrar para construir e compreender sentidos.

$\mathrm{Na}$ sequência da atividade, retornamos no dia 10 de agosto do presente ano, em dois períodos, e aplicamos a leitura individual do infográfico "Água" (RICHARDS; SIMKINS, 2013, p. 108-109). Cada aluno recebeu o infográfico colorido e respondeu individualmente a 16 questões organizadas a fim de investigar o nível de leitura de um texto multimodal. Os objetivos da atividade foram os mesmos citados na prática do dia 8 de agosto, embora de forma individual e escrita para observar o desenvolvimento de um exercício de leitura num texto multimodal. Ao analisarmos a Base Nacional Comum Curricular (BRASIL, 2018) nas práticas de linguagem, percebemos que uma das mudanças foi a inserção da "semiótica" nas habilidades, uma referência ao estudo de textos com múltiplas linguagens, como, por exemplo, os infográficos.

Averiguemos o que os estudantes demonstraram a partir da leitura do infográfico, pois sabemos que o leitor precisa ser considerado, na perspectiva bakhtiniana, sob uma atitude responsiva ativa, mediante "pergunta-resposta, afirmação-objeção, afirmação-concordância, etc" (BAKHTIN, 2016, p. 30), ou seja, em um propósito dialógico. Bakhtin (2016) postula o dialogismo como interação, pois é um produto histórico, marcado de forma social e cultural. Os eventos de letramento e multiletramentos se concretizam pelos gêneros do discurso, em nosso caso, o infográfico.

Observemos a síntese exposta no Quadro 1 no qual constam abordagens referentes ao infográfico "Água" (RICHARDS; SIMKINS, 2013, p. 108-109), com base no questionário aplicado aos alunos do $2^{\circ}$ ano do ensino médio.

Quadro 1- Síntese das questões do infográfico: “Água” .

\begin{tabular}{|c|c|c|c|}
\hline $\begin{array}{l}\text { Técnica da coleta } \\
\text { Questionário do } \\
\text { Infográfico Água } \\
\text { (apêndice C). }\end{array}$ & Habilidade & Resposta esperada & Resposta do aluno \\
\hline $\begin{array}{l}\text { 1-Que elementos } \\
\text { englobam, na sua } \\
\text { apresentação, esse } \\
\text { infográfico? }\end{array}$ & $\mid$\begin{tabular}{lcr} 
Identificar & \multicolumn{2}{c}{ informações } \\
verbais & e & não-verbais que \\
estruturam & o & gênero \\
discursivo infográfico.
\end{tabular} & $\begin{array}{l}\text { Verificar a atenção na } \\
\text { leitura identificando todas } \\
\text { as informações verbais, } \\
\text { não-verbais, como a } \\
\text { presença de desenhos, } \\
\text { números e gráfico. }\end{array}$ & $\begin{array}{l}\text { Os alunos em sua maioria } \\
\text { identificaram informações } \\
\text { verbais e não-verbais, } \\
\text { desenho, números e o } \\
\text { gráfico. }\end{array}$ \\
\hline $\begin{array}{lr}2-\quad \text { Observe } & \text { o } \\
\text { infográfico } & \\
\text { "Água": O } & \text { que } \\
\text { você } & \text { observou } \\
\text { primeiro } & \text { que } \\
\text { chamou mais } & \text { sua } \\
\text { atenção? } & \\
\end{array}$ & $\begin{array}{l}\text { Perceber a importância da } \\
\text { imagem na constituição do } \\
\text { texto multimodal. }\end{array}$ & $\begin{array}{l}\text { Que imagem chamou } \\
\text { mais a atenção. }\end{array}$ & $\begin{array}{l}99 \% \text { dos alunos } \\
\text { observaram primeiro as } \\
\text { imagens. }\end{array}$ \\
\hline 3- Existe uma & Observar que as informações & A resposta esperada é que & A maioria dos alunos \\
\hline
\end{tabular}


Volume 14 - Número 2 - ago/dez de 2019

\begin{tabular}{|c|c|c|c|}
\hline $\begin{array}{l}\text { ordem, que segue } \\
\text { uma sequência na } \\
\text { leitura dessas } \\
\text { informações? }\end{array}$ & $\begin{array}{l}\text { do infográfico não estão } \\
\text { postas aleatoriamente }\end{array}$ & $\begin{array}{l}\text { há um percurso linear de } \\
\text { leitura nesse texto. }\end{array}$ & $\begin{array}{l}\text { afirmou ter uma } \\
\text { sequência linear na leitura } \\
\text { do infográfico. }\end{array}$ \\
\hline \begin{tabular}{|lr} 
4- O que você \\
levou & em \\
consideração para a \\
leitura & desse \\
infográfico? & \\
\end{tabular} & $\begin{array}{l}\text { Perceber que há interação } \\
\text { simultânea entre imagens e } \\
\text { palavras }\end{array}$ & $\begin{array}{l}\text { A resposta esperada era a } \\
\text { leitura do verbal e do } \\
\text { visual ao mesmo tempo }\end{array}$ & $\begin{array}{l}99 \% \text { dos alunos levaram } \\
\text { em conta a leitura do } \\
\text { verbal e do não-verbal ao } \\
\text { mesmo tempo. }\end{array}$ \\
\hline $\begin{array}{l}\text { 5- Qual a } \\
\text { frequência } \quad \text { de } \\
\text { contato que você } \\
\text { tem com esse tipo } \\
\text { de texto? }\end{array}$ & $\begin{array}{l}\text { Pergunta complementar que } \\
\text { constata o não uso do gênero } \\
\text { infográfico na sala de aula. }\end{array}$ & $\begin{array}{l}\text { A resposta esperada seria } \\
\text { que esse gênero muito } \\
\text { recorrente na atualidade } \\
\text { fosse utilizado no ensino } \\
\text { com frequência, mas não } \\
\text { o é. }\end{array}$ & $\begin{array}{l}99 \% \text { dos alunos não } \\
\text { conhecia o infográfico } \\
\text { como gênero discursivo. }\end{array}$ \\
\hline $\begin{array}{l}\text { 6- Você considera a } \\
\text { leiturar desse } \\
\text { infográfico: } \\
\text { ( ) fácil } \\
\text { ( ) difícil }\end{array}$ & $\begin{array}{l}\text { Pergunta complementar, não é } \\
\text { uma habilidade. }\end{array}$ & $\begin{array}{l}\text { A resposta esperada era } \\
\text { que sim, pois é uma } \\
\text { linguagem jornalística } \\
\text { mais visual, isso não quer } \\
\text { dizer que seja de modo } \\
\text { artificiosa ou apreendida } \\
\text { com rapidez. }\end{array}$ & $\begin{array}{l}100 \% \text { considerou fácil a } \\
\text { leitura do texto por ter } \\
\text { uma linguagem direta, } \\
\text { objetiva e acessível em } \\
\text { que as imagens, cores e } \\
\text { palavras auxiliam na } \\
\text { construção do sentido. }\end{array}$ \\
\hline $\begin{array}{l}\text { 7- Você prefere ler } \\
\text { textos: } \\
\text { ( ) somente verbais } \\
\text { ( ) verbo-visuais }\end{array}$ & $\begin{array}{l}\text { Pergunta complementar, não é } \\
\text { habilidade }\end{array}$ & $\begin{array}{l}\text { A resposta esperada era } \\
\text { que preferissem ler textos } \\
\text { multimodais, } \\
\text { característica básica dos } \\
\text { textos contemporâneos. }\end{array}$ & $\begin{array}{l}\text { A maioria tem preferência } \\
\text { por textos verbo-visuais } \\
\text { (multimodais). }\end{array}$ \\
\hline $\begin{array}{l}\text { 8- Se o texto } \\
\text { apresentado fosse } \\
\text { somente verbal ou } \\
\text { somente visual o } \\
\text { sentido do texto } \\
\text { seria o mesmo? }\end{array}$ & $\begin{array}{l}\text { Percepção da associação dos } \\
\text { dois } \\
\text { (multimodalidade). }\end{array}$ & $\begin{array}{l}\text { A resposta esperada era } \\
\text { não, pois a associação das } \\
\text { informações verbais e } \\
\text { visuais se integram e } \\
\text { auxiliam o entendimento } \\
\text { do tema central. }\end{array}$ & $\begin{array}{l}75 \% \text { dos alunos } \\
\text { respondeu que se o texto } \\
\text { fosse criado em um só } \\
\text { modo o sentido não seria } \\
\text { o mesmo. }\end{array}$ \\
\hline $\begin{array}{l}\text { 9- Qual a melhor } \\
\text { afirmativa que } \\
\text { resume a ideia do } \\
\text { infográfico? }\end{array}$ & $\begin{array}{l}\text { Inferir sobre a compreensão } \\
\text { do texto como um todo a } \\
\text { partir de informações } \\
\text { observadas no infográfico. }\end{array}$ & $\begin{array}{l}\text { Esperávamos que os } \\
\text { alunos entendessem que o } \\
\text { texto tematiza o } \\
\text { panorama da utilização da } \\
\text { água potável no mundo. }\end{array}$ & $\begin{array}{l}50 \% \text { da turma inferiu } \\
\text { corretamente. }\end{array}$ \\
\hline $\begin{array}{l}10-\text { De que forma } \\
\text { essa temática } \\
\text { influencia na vida } \\
\text { das pessoas? }\end{array}$ & Opinar sobre o tema tratado. & $\begin{array}{l}\text { A resposta esperada era } \\
\text { de que essa temática } \\
\text { influencia diretamente na } \\
\text { vida das pessoas e apela } \\
\text { para a conscientização do } \\
\text { bom uso da água. }\end{array}$ & $\begin{array}{l}80 \% \text { dos alunos afirmou } \\
\text { que o tema é relevante, } \\
\text { faz refletir sobre o } \\
\text { problema da água potável } \\
\text { no mundo. }\end{array}$ \\
\hline $\begin{array}{l}11-\text { Descreva as } \\
\text { informações mais } \\
\text { relevantes, no seu } \\
\text { entendimento, do } \\
\text { texto comentando- } \\
\text { as }\end{array}$ & $\begin{array}{l}\text { Relacionar as partes que } \\
\text { compõem o infográfico, } \\
\text { identificar qual parte do texto } \\
\text { os alunos entenderam como } \\
\text { mais importante. }\end{array}$ & $\begin{array}{l}\text { Pretendíamos que os } \\
\text { alunos mencionassem } \\
\text { todos os itens com as } \\
\text { informações: quantidade } \\
\text { de água doce no planeta; } \\
\text { acesso à água potável; } \\
\text { sobre a quantidade de } \\
\text { garrafas de água } \\
\text { compradas; países que } \\
\text { gastam mais ou menos } \\
\text { água; uso da água no } \\
\text { banho e sobre a água }\end{array}$ & $\begin{array}{l}\text { As informações citadas } \\
\text { pelos alunos foram sobre } \\
\text { a porcentagem de água } \\
\text { doce no planeta, sobre os } \\
\text { países que gastam mais } \\
\text { água e os que gastam } \\
\text { menos água no mundo. } \\
\text { Apenas uma aluna citou } \\
\text { todas essas informações } \\
\text { constantes no infográfico. }\end{array}$ \\
\hline
\end{tabular}


Volume 14 - Número 2 - ago/dez de 2019

\begin{tabular}{|c|c|c|c|}
\hline & & $\begin{array}{l}\text { usada na produção de } \\
\text { alimentos. }\end{array}$ & \\
\hline $\begin{array}{lr}\text { 12-A leitura } & \text { do } \\
\text { infográfico roi } & \text { foi } \\
\text { suficiente r para } \\
\text { você compreender } \\
\text { as informações? }\end{array}$ & $\begin{array}{l}\text { Pergunta complementar, não é } \\
\text { habilidade }\end{array}$ & $\begin{array}{l}\text { A resposta esperada era } \\
\text { sim. Reter as informações } \\
\text { para que sejam usadas em } \\
\text { outros contextos. }\end{array}$ & $\begin{array}{l}\text { Todos responderam que } \\
\text { sim. }\end{array}$ \\
\hline $\begin{array}{l}\text { 13- Você confia nas } \\
\text { informações desse } \\
\text { infográfico? }\end{array}$ & 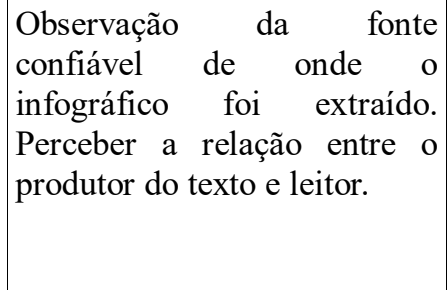 & 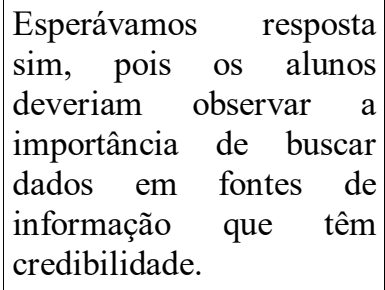 & $\begin{array}{l}75 \% \text { disse confiar nas } \\
\text { informações do texto } \\
\text { retirado de um livro. Os } \\
\text { demais não observaram a } \\
\text { fonte. }\end{array}$ \\
\hline $\begin{array}{l}\text { 14- Observe as } \\
\text { cores utilizadas no } \\
\text { infográfico } \\
\text { “Água”. Como a } \\
\text { cor dos elementos } \\
\text { textuais } \\
\text { influenciam r na } \\
\text { leitura? }\end{array}$ & $\begin{array}{l}\text { Identificar informações no } \\
\text { visual (cores) }\end{array}$ & $\begin{array}{lr}\text { A resposta sim, porque } \\
\text { cor é importante na } \\
\text { composição } & \text { do } \\
\text { infográfico em virtude de } \\
\text { suas características } \\
\text { atração visual } \\
\text { associação semântica. }\end{array}$ & $\begin{array}{l}\text { Todos os alunos } \\
\text { assinalaram que a cor é } \\
\text { importante na construção } \\
\text { do sentido, devido a } \\
\text { chamar a atenção e causar } \\
\text { impacto no leitor. }\end{array}$ \\
\hline $\begin{array}{llr}15- & O & \text { layout } \\
\text { (fonte) das } & \text { letras } \\
\text { influencia } & \text { na } \\
\text { leitura do texto? }\end{array}$ & $\begin{array}{l}\text { Identificar } \quad \text { informações } \\
\text { visuais das letras (layout) }\end{array}$ & $\begin{array}{l}\text { O formato do layout é um } \\
\text { modo de expressão, } \\
\text { portanto influencia, sim, } \\
\text { na leitura e sua } \\
\text { compreensão. }\end{array}$ & $\begin{array}{l}90 \% \text { dos alunos afirmou } \\
\text { que o layout gráfico } \\
\text { influencia na leitura. }\end{array}$ \\
\hline $\begin{array}{l}\text { 16- Qual parte do } \\
\text { infográfico que, na } \\
\text { sua opinião, melhor } \\
\text { deixar claro r o } \\
\text { assunto rrínlo - o } \\
\text { tratado: o título } \\
\text { texto introdutório - } \\
\text { as imagens. }\end{array}$ & $\begin{array}{l}\text { Opinar sobre a leitura que o } \\
\text { aluno fez do texto com base } \\
\text { na estrutura que o caracteriza, } \\
\text { e sobre qual modo contribuiu } \\
\text { mais para o entendimento. }\end{array}$ & $\begin{array}{l}\text { Não havia uma resposta } \\
\text { correta. }\end{array}$ & $\begin{array}{l}40 \% \text { afirmou que o texto } \\
\text { introdutório foi a parte } \\
\text { que melhor deixou claro o } \\
\text { assunto do infográfico, } \\
35 \% \text { destacou as imagens, } \\
15 \% \text { o título e } 10 \% \text { não } \\
\text { entenderam a questão. }\end{array}$ \\
\hline
\end{tabular}

\section{Fonte: Elaborado pelos pesquisadores}

Com base nas questões formuladas e apresentadas nesse Quadro1, passamos a analisar algumas questões que consideramos mais pertinentes no sentido de esclarecer a questão norteadora deste estudo: a prática leitora com texto multimodal, pouco utilizado nas aulas de língua materna, possibilita contribuir com o letramento e os multiletramentos do referido alunado.

A primeira questão foi sobre identificar quais elementos englobam, na sua apresentação, o infográfico “Água” (RICHARDS; SIMKINS, 2013, p. 108-109). Os alunos poderiam marcar todas as alternativas com as quais concordassem. Percebemos que alguns alunos não prestaram bem atenção à leitura do texto, pois não havia no infográfico a presença de fotografia, mesmo assim, 11\% dos alunos marcaram como se a tivessem visto. Há a presença de gráfico não da forma tradicional, e sim com a imagem dos copos d'água para mostrar a porcentagem de água doce no mundo; $70 \%$ dos alunos marcaram essa alternativa. Também alguns alunos (40\%) não marcaram números presentes no texto, outros $(45 \%)$ não marcaram sobre a presença de desenhos e apenas um não identificou informações escritas. Constatamos que alguns alunos teriam sua leitura comprometida numa avaliação e também no cotidiano como um leitor cidadão. 
Ao analisarmos, sob a ótica de Bakhtin (2016), podemos afirmar que o infográfico é um gênero discursivo que contempla na sua construção composicional uma estrutura (desenho, gráfico, a presença de elementos verbais e não-verbais), a qual precisa ser observada pelo estudante, bem como as escolhas dos recursos linguísticos (estilo) para gerar, assim, sentido completo, e o tema como abordagem e sentido produzido em um dado discurso, tomado como um todo na sua significação. Rojo (2012, p. 19) afirma sobre a multimodalidade ou multissemiose dos textos atuais, que exigem multiletramentos, ou seja, "capacidades e práticas de compreensão" para fazer significar. Além disso, Lemke (2010) comenta que o desafio hoje são as práticas escolares de leitura e escrita que estão defasadas há muito tempo para uma geração "nativo digital".

Quando perguntados, na questão 4, sobre o que levaram em consideração para a leitura do infográfico, $99 \%$ dos alunos informaram levar em conta a leitura do verbal e do visual ao mesmo tempo. Ativamos aqui Dionísio (2011, p. 148) ao exprimir que a leitura de um infográfico pode ser feita de várias maneiras como: ler o texto como um todo; ler apenas o texto verbal e olhar as imagens; no entanto, a leitura do infográfico exige apreciação simultânea de imagens e palavras que interagem entre si. No caso do infográfico "Água”, a leitura se dá da parte superior para inferior e da esquerda para a direita - foi essa ordem que os alunos observaram. Assim, constatamos, pela maioria, que a compreensão das informações aconteceu efetivamente quando as informações verbais e visuais se processaram simultaneamente, bem como que a integração dos modos de leitura auxilia para o entendimento do tema central.

Lemke (2010, p. 462) destaca que "o texto significa mais quando justaposto à figura, e a mesma forma à figura quando colocada ao lado de um texto". Além disso, é preciso auxiliar os alunos a compreenderem como "ler o texto de forma diferente e interpretar a imagem de forma diferente, em função da presença um do outro" (LEMKE, 2010, p. 462). Esse letramento é exigido pelos diversos gêneros discursivos atuais, visto que há uma expansão dessa noção para o "campo da imagem, da música, das outras semioses que não somente a escrita" (ROJO, 2009, p. 107), pois isso se tornou uma necessidade no uso da linguagem com a influência da tecnologia.

Ao serem questionados (questão 5) sobre qual a frequência de contato que possuem com esse gênero, 99\% dos alunos responderam que raramente o leem. Isso posto, confirmamos, de acordo com Ribeiro (2016, p. 42), que "os textos imagéticos são pouco trabalhados nas escolas, sendo comum que apareçam apenas como complemento do texto escrito ou ilustração "em diálogo" com esse texto". A turma toda, na questão 6, considerou fácil a leitura do infográfico, explicando que "o texto segue uma ordem cronológica de leitura"; manifestaram que "houve clareza nas informações"; que "as imagens e as cores ajudaram a entender muito melhor o texto".

Nesse sentido, Ribeiro (2016), citando Cairo (2008, p. 30, grifo do autor), alerta que não se pode afirmar que a leitura de qualquer infográfico seja "necessariamente mais simples ou mais rápida do que a do texto", pois "a visualização na imprensa não quer dizer que a informação é simplificada no sentido de reduzi-la de modo artificioso para que possa ser apreendida com rapidez por leitores pouco ilustrados".

Quando perguntados, na questão 7, se "Você prefere ler textos: somente visuais ou verbo-visuais?", a maioria dos alunos mostrou ter preferência por textos verbo-visuais. Com isso, observamos a escolha da maioria pelos textos multimodais que exigem letramentos multissemióticos, conforme Rojo (2009) nos aponta. Esse letramento é exigido pelos textos modernos, havendo assim um alargamento dessa noção para o "campo da imagem, da música, das outras semioses que não somente a escrita" (ROJO, 2009, p. 107). Isso se tornou uma necessidade no uso da linguagem com a influência da tecnologia. O conceito de multimodalidade, segundo Kress (2000), nos força a repensar as distinções feitas entre 
Volume 14 - Número 2 - ago/dez de 2019

comunicação e uso, em particular entre leitura e uso, o que é crucial para a teoria dos multiletramentos, em que a leitura, enquanto prática cultural semiótica, se vale dos significados apreendidos.

$\mathrm{Na}$ questão 9, perguntamos sobre a melhor afirmativa que resume a ideia do infográfico. Esse questionamento foi sobre a compreensão do texto como um todo, sendo que havia quatro alternativas e apenas duas foram assinaladas, dividindo a turma: para $50 \%$, a alternativa que possui a ideia central do texto é a seguinte: "É sobre o panorama da utilização da água potável no mundo"; essa é a alternativa correta. Metade da turma teve dificuldade na apreensão da ideia central do infográfico. De acordo com o que prevê a BNCC (BRASIL, 2018), a habilidade da leitura é um dos eixos que representam práticas de linguagem, que já no Ensino Fundamental precisa ser desenvolvido com o texto multimodal. Nesse movimento de aprendizagem para o (multi)letramento, entendemos que o desenvolvimento da habilidade de leitura não é fácil, pois é um complexo processo cognitivo na produção de sentidos.

$\mathrm{Na}$ sequência desta análise, damos foco à questão 10: "De que forma essa temática influencia na vida das pessoas?", $80 \%$ nas suas respostas apontaram que a temática "faz refletir sobre o problema da utilização da água potável no mundo"; é "conscientização sobre uso, acesso, desperdício"; "influencia de forma intensa porque é um assunto que abrange a todos no presente e no futuro". Aqui percebemos o infográfico como gênero discursivo usado como um meio de apreender a realidade que cumpre seu objetivo de informar, também que a atividade escolar precisa mostrar para que serve a leitura na vida e que o aluno faça a relação entre a leitura e práticas sociais para além da escola. Conforme Bakhtin (2016), quanto às características do gênero, o conteúdo temático, no caso do infográfico, mostra a especificidade de sua esfera, sua função, pois é a explicação sobre as informações, estatísticas, etc. No estilo da linguagem considera além dos recursos linguísticos, as semioses que são modos de significar (cores, por exemplo). Na construção composicional, é preciso considerar também as multimodalidades como as imagens, a escrita, a tipologia textual etc. Assim, as situações de comunicação envolvem as práticas de multiletramentos que modificam as formas de interação e recepção dos textos e suas temáticas.

Cope e Kalantzis (2000) reiteram que os estudantes precisam se ver como participantes ativos nas mudanças sociais, só assim, estarão desenvolvendo o espírito crítico, se tornando multiletrados capazes de participar das práticas sociais como cidadão.

Encaminhamos, para finalizar, a análise da questão 15. Perguntamos "se o layout gráfico (fonte) das letras influencia na leitura": $90 \%$ dos alunos disseram que o layout influencia na leitura. Justificaram que "o tamanho e formato das letras ajudam a chamar a atenção do leitor", "pois deixa certas informações mais explícitas"; "o destaque em negrito, tamanho, forma influencia para sabermos o que é o título, subtítulo, texto. Além de deixar o infográfico com um design interessante". De acordo com Kress (2003), até o layout - a formatação do texto - é um modo de expressão. Dionísio (2011, p. 145) menciona que o layout "auxilia na identificação do gênero, dependendo da familiaridade do leitor com o suporte textual, o leitor poderá também reconhecê-lo".

Diante do até aqui comentado, ressaltamos que Kress e van Leeuwen (2006) discorrem sobre aspectos teóricos que auxiliam a trabalhar no ensino e que ajudam a compreender mais e melhor práticas de leitura, com a finalidade de que possamos lidar de forma adequada com os textos multimodais emergentes, visto que há nessas linguagens que se espraiam no e pelo texto uma nova construção de significados. No caso desse estudo, o trabalho com infográfícos revela a possibilidade de multiletrar os alunos ampliando a rede colaborativa pela possibilidade de trabalhar assuntos e com professores de diversas áreas.

Desse modo, passou a existir uma preocupação em torno de discussões acerca da influência do contexto atual diversificado e tecnológico sobre a escola para que os alunos tenham um (multi)letramento autônomo. Percebemos que é necessário trabalhar com essas 
Volume 14 - Número 2 - ago/dez de 2019

questões nas aulas de língua materna considerando as condições sociais, culturais e econômicas que são inerentes à vida social. Bakhtin (2016) ressalta que quando o texto adquire o caráter social, ele passa a ter uma configuração dialógica em relação aos sujeitos envolvidos. Reforça, ainda, a importância do diálogo na interação entre os sujeitos, o que determina a compreensão do texto; essa interação é muito relevante por ser também uma interação com a sociedade.

O dialogismo está ligado ao conceito de compreensão responsiva ativa (BAKHTIN, 2016), pois, através dessa prática, mobilizaram-se experiências históricas e socialmente construídas que foram ativadas para os alunos emitirem uma resposta a um discurso (infográfico) em que eles demarcaram uma posição, um juízo de valor do locutor numa esfera de comunicação. Essa compreensão favorece uma atitude e toda a leitura é suscetível de uma responsividade que provém das interações sociais.

A leitura de um texto multimodal, conforme prática desenvolvida em sala de aula e aqui apresentada e analisada, é uma singela demonstração daquilo que pode ser feito em sala de aula nas aulas de língua materna, nas mais diversas condições de trabalho. Sabemos que podemos avançar mais até a produção de infográficos, pois são muitas as possibilidades para trabalhar com o texto.

\section{Considerações finais}

Este trabalho tematizou a experiência da leitura de um infográfico enquanto gênero discursivo multimodal no contexto escolar. O questionamento norteador da pesquisa foi averiguar se o desenvolvimento de uma prática leitora com um texto multimodal pouco utilizado, nas aulas de língua materna, possibilita contribuir com os multiletramentos do referido alunado.

O resultado da pesquisa mostrou que práticas leitoras bem elaboradas com a utilização de textos multimodais como os infográficos promovem de forma eficaz os multiletramentos. Essas práticas aproximam os estudantes de situações sociodiscursivas próprias do cotidiano, por ser um instrumento que ajuda o aluno a estruturar seu conhecimento e refletir tanto no que diz respeito à língua materna, quanto em outras disciplinas. Consideramos ser importante debatermos na escola, nas aulas de língua materna, como espaço de multiplicidade cultural, textos multimodais para que se construa uma compreensão inclusiva sobre leitura e linguagem na contemporaneidade. Ao realizar a experiência prática, constatamos existir desconhecimento do gênero em questão por parte dos alunos e sua professora regente, no entanto, ressaltamos o crescente prestígio do infográfico na mídia. Os alunos e a professora mostraram-se muito interessados e envolvidos nas aulas da prática leitora.

As possíveis contribuições dadas neste estudo mostram a necessidade de se investir na formação do professor multiletrado, para que ele forme leitores também multiletrados com conhecimento e competência, utilizando a multiplicidade de formas de interação e de comunicação usadas para promover leitura e compreensão de sentidos. O educador nesse contexto é fundamental porque auxiliará o aluno no desenvolvimento de sua competência linguística, bem como na sua inserção social e cultural.

Além disso, a pesquisa contribuiu no sentido de apontar que o gênero multimodal utilizado - o infográfico - possibilita dinamicidade com a finalidade de desenvolver e aprimorar competências leitoras que levam aos multiletramentos. Não temos dúvida de que essa prática social com textos multimodais têm um papel relevante na leitura significativa das diversas linguagens que se potencializam através da tecnologia. Por isso, é importante pensar em práticas leitoras com textos que se configurem por múltiplas linguagens, atividade contínua e gradativa, de modo que o ensino de língua materna assuma um papel mais significativo na medida em que aproxima o aluno de uma situação real da língua, promovendo 
assim a aprendizagem mais prazerosa, concreta e proveitosa e, por consequência, nutrindo o letramento e os multiletramentos dos estudantes, jovens leitores.

Enfim, por meio de um olhar investigativo, crítico, foi dado significância ao processo de ensino e aprendizagem da língua enquanto sistema vivo e necessário à interação humana. É por meio dos gêneros discursivos que a interação se efetiva, em especial letramento/multiletramentos de alunos no ensino médio. A escola precisa assumir seu papel de local do "cidadão do mundo" e aproximar os estudantes de gêneros discursivos que façam parte do seu cotidiano para que assumam o papel de leitor crítico diante da demanda de informações recebidas.

\section{Referências}

BAKHTIN, Mikail. Os gêneros do discurso. In: Os gêneros do discurso.

Organização, tradução, posfácio e notas Paulo Bezerra. 1. ed. São Paulo: Editora 34 LTDA, 2016. p. 11-69.

BRASIL. Parâmetros curriculares nacionais: introdução aos parâmetros curriculares nacionais. Secretaria de Educação Fundamental - Brasília: MEC/SEF, 1997.

BRASIL. Base Nacional Comum Curricular (BNCC). Brasília, MEC/CONSED/UNDIME, 2018. Disponível em: <http://basenacionalcomum.mec.gov.br/abase >. Acesso em: 03 jun. 2019.

BRASIL. Base Nacional Comum Curricular: Ensino Médio. Brasília, MEC/CONSED/UNDIME, 2018. Disponível em: < http://portal.mec.gov.br/conselhonacional-de-educacao/base-nacional-comum-curricular-bncc-etapa-ensino-medio $>$. Acesso em: 08 ago. 2018.

CAIRO, Alberto. Infografia 2.0 Visualización interactiva de información em prensa. Madri: Alamut, 2008.

COPE, Bill.; KALANTZIS, Mary. Introduction: the beginnings of an idea. In:

Multiliteracies: literacy learning and the design of social futures. London: Routledge, 2000. p. 3-8.

DIONISIO, Angela Paiva. Gêneros textuais e multimodalidade. In: KARWOSKI, Acir Mário; GAYDECZKA, Beatriz; BRITO, Karim Siebeneicher (Orgs.). Gêneros textuais: reflexões e ensino. 4. ed. São Paulo: Parábola Editorial, 2011. p. 137-173.

DIONÍSIO, Angela Paiva.; VASCONCELOS, Leila Janot de. Multimodalidade, gênero textual e leitura. In: BUNZEN Clecio.; MENDONÇA Márcia.(org). Múltiplas linguagens para o Ensino Médio. São Paulo: Parábola Editorial, 2013. p. 19-42.

. Multimodalidade, capacidade de aprendizagem e leitura. In: BUNZEN Clecio.; MENDONÇA Márcia. (org). Múltiplas linguagens para o Ensino Médio. São Paulo: Parábola Editorial, 2013. p. 43-67.

KLEIMAN, Angela. Texto e leitor: aspectos cognitivos da leitura. Campinas, São Paulo: Pontes, 2002. 
Volume 14 - Número 2 - ago/dez de 2019

KRESS, Gunther. Multimodality. In: COPE, Bill; KALANTZIS, Mary. Multiliteracies: literacy learning and the design of social futures. London: Routledge, 2000. p. 182-202.

KRESS, Gunther; VAN LEEUWEN Theodore. Introduction. Traducción: Laura H. Molina, para la cátedra de Producción de Textos de la FBA, UNLP, 2011. In: Multimodal discourse: the modes and media of contemporary communication. Londres: Arnold, 2001. p. $1-23$.

Reading images. The gramar of visual design. 2. ed. London: Routledge, 2006.

LEMKE, J. L. Letramento metamidiático: transformando significados e mídias. In. Revista Trabalhos em Linguística Aplicada, Campinas, SP: IEL/UNICAMP, 2010. p. 49(2): 455479. Disponível em: $<$ http://www.scielo.br/scielo.php?script=sci_arttext\&pid=S0103$18132010000200009 \& \operatorname{lng}=\mathrm{en} \& n r m=\mathrm{iso}>$. Acesso em: 2 ago. $20 \overline{1} 8$.

PRODANOV, Cleber Cristiano; FREITAS, Ernani Cesar de. Metodologia do trabalho científico: métodos e técnicas da pesquisa e do trabalho acadêmico. Novo Hamburgo: Editora Feevale, 2013. Disponível em: < http://www.ebah.com.br/content/ABAAAg0OwAA/prodanov-freitas-metodologia-trabalhocientifico-metodos-tecnicas-pesquisa-trabalho-academico>. Acesso em: 20 out. 2019.

RIBEIRO, Ana Elisa. Ler na tela - letramento e novos suportes de leitura escrita. In: Letramento digital: aspectos sociais e possibilidades pedagógicas. Carla Coscarelli, Ana Elisa Ribeiro (Orgs.). 3. ed. Belo Horizonte: Ceale; Autêntica, 2011. p. 125- 150.

Textos multimodais: leitura e produção. São Paulo: Parábola Editorial, 2016.

RICHARDS, Jon.; SIMKINS, Ed. O mundo em infográficos. [tradução de Liliana Negrello, Orlei Negrello Filho]; Rio de Janeiro: Sextante, 2013.

ROJO, Roxane. Letramento múltiplos, escola e inclusão social. São Paulo: Parábola Editorial, 2009.

. Pedagogia dos multiletramentos: diversidade cultural e de linguagens na escola. In: Roxane Helena R.; MOURA, Eduardo (Coord.). Multiletramentos na escola. São Paulo: Parábola, 2012. p. $11-31$.

ROJO, Roxane; JIMENEZ, Márcia Coutinho Ramos. A leitura do hipertexto no contexto de formação de educadores | Desafios dos (multi)letramentos nas nuvens. Revista Na Ponta do Lápis, São Paulo, n. 22, ago. 2013. Disponível em:

$<$ https://www.escrevendoofuturo.org.br/EscrevendoFuturo/arquivos/968/NPL22.pdf $>$. Acesso em: 2 out. 2019.

SANCHO, José Luis Valero. La infografía de prensa. Ámbitos: Revista Internacional de Comunicación, v. 4, n. 2, p. 38-48, 2013. Disponível em:

$<$ http://www.periodicos.ufc.br/passagens/article/view/1166>. Acesso em: 23 jul. 2018.

THE NEW LONDON GROUP. A pedagogy of Multiliteracies: designing social futures. In: COPE, BILL; KALANTZIS, M. Multiliteracies: Literacy learning and the design of social futures. London: Routledge, 2000. p. 9-37. 